Miami Nature Biotechnology Short Reports

TheScientificWorld (2001) 1(S3), 85SR

ISSN 1532-2246; DOI 10.1100/TSW.2001.114

\title{
MECHANISMS INVOLVED IN THE ENHANCED SUSCEPTIBILITY OF SENESCENT RATS TO THE HEPATOCARCINOGENIC EFFECT OF PEROXISOME PROLIFERATORS: ROLE OF PEROXISOME PROLIFERATOR-ACTIVATED RECEPTOR ALPHA (PPAR $\alpha)$, CELL PROLIFERATION AND OXIDATIVE STRESS
}

\author{
Jihan A. Youssef ${ }^{1}$, Pierre Ammann², Burhan L. Ghanayem² ${ }^{2}$, Linda S. Birnbaum ${ }^{3}$ and Mostafa \\ Z. Badr $^{1, *}$ \\ ${ }^{1}$ University of Missouri-Kansas City, Kansas City, MO 64108, ${ }^{2}$ National Institute of \\ Environmental Health Sciences, Research Triangle Park, NC 27709 and ${ }^{3}$ US Environmental \\ Protection Agency, Research Triangle Park, NC 27709 \\ Badrm@UMKC.edu
}

INTRODUCTION. Nongenotoxic peroxisome proliferating chemicals (PPs) cause hepatocarcinogenesis in rodents, with senescent animals being more susceptible than their younger counterparts (1). Theories have been advanced suggesting a PPAR $\alpha$-dependent role involving Kupffer cells, growth regulating genes, or oxidative stress in PP-induced hepatocarcinogenecity. The purpose of this study was to investigate mechanisms involved in the enhanced susceptibility of senescent animals to these chemicals.

METHOD. Using RT-PCR, we investigated age-dependent hepatic gene expression of PPAR $\alpha$, proliferating cell nuclear antigen (PCNA), and the $\mathrm{H}_{2} \mathrm{O}_{2}$-producing peroxisomal enzyme acyl-CoA Oxidase (Acose) in male Fischer-344 rats of 4, 10, 50 and 100 weeks of age. PPs used were: Diethylhexylphthalate (DEHP, $1.2 \mathrm{~g} / \mathrm{kg}), \mathrm{Wy}-14,643$ (250 mg/kg), and clofibrate $(250 \mathrm{mg} / \mathrm{kg})$, given orally in $1 \mathrm{ml}$ corn oil. Control animals received the corn oil vehicle. All animals were sacrificed 48 hrs post dose.

RESULTS. DEHP, and Wy-14,643 increased liver/body weight ratios more dramatically in young animals (4 weeks old), than in all other age groups within 48 hrs. Clofibrate did not cause hepatomegaly in any group. Despite a significant difference in the hepatocarcinogenic potency of Wy-14,643 and DEHP (2), these two PPs increased hepatic expression of PCNA to comparable levels in all age groups. Ironically, clofibrate which is a weak hepatocarcinogen (2) increased PCNA mRNA expression to significantly higher levels in 4-week-old rats compared to 100-week-old rats. In addition, Wy-14,643 enhanced the expression of Acose mRNA to comparable levels in all age groups, while clofibrate increased the expression of this gene to higher levels in young, adult rats (10 weeks old), than in senescent rats (100 weeks old).

DISCUSSION. Data suggest that hepatic levels of PPAR $\alpha$ gene expression, cell proliferation, or oxidative stress do not adequately explain the known enhanced susceptibility of the aged liver to PP-induced hepatocarcinogenecity. This conclusion is supported by our findings showing that age-related changes in these parameters, in response to treatment with PPs, did not correspond with the known rank of hepatocarcinogenic potencies of the tested chemicals. 
Other factors such as the impact of aging on PP-induced inhibition of hepatocellular apoptosis remain to be evaluated.

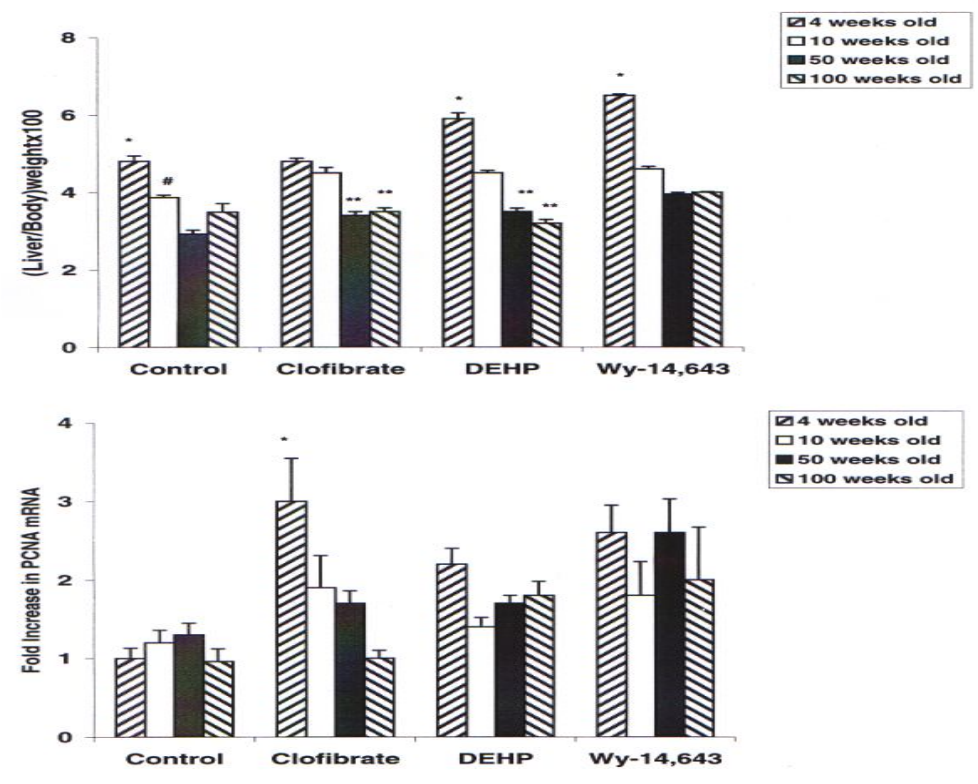

ACKNOWLEDGEMENTS. This work was supported by NIH grants CA/OD 74384 and AG 18479; this abstract does not necessarily reflect EPA policy.

\section{REFERENCES.}

1. $\quad$ Youssef, J. and Badr, M. (1999) Environ. Health Perspect. 107, 791-797

2. Youssef, J. and Badr, M. (1998) CRC Crit. Rev. Toxicol. 28, 1-33 

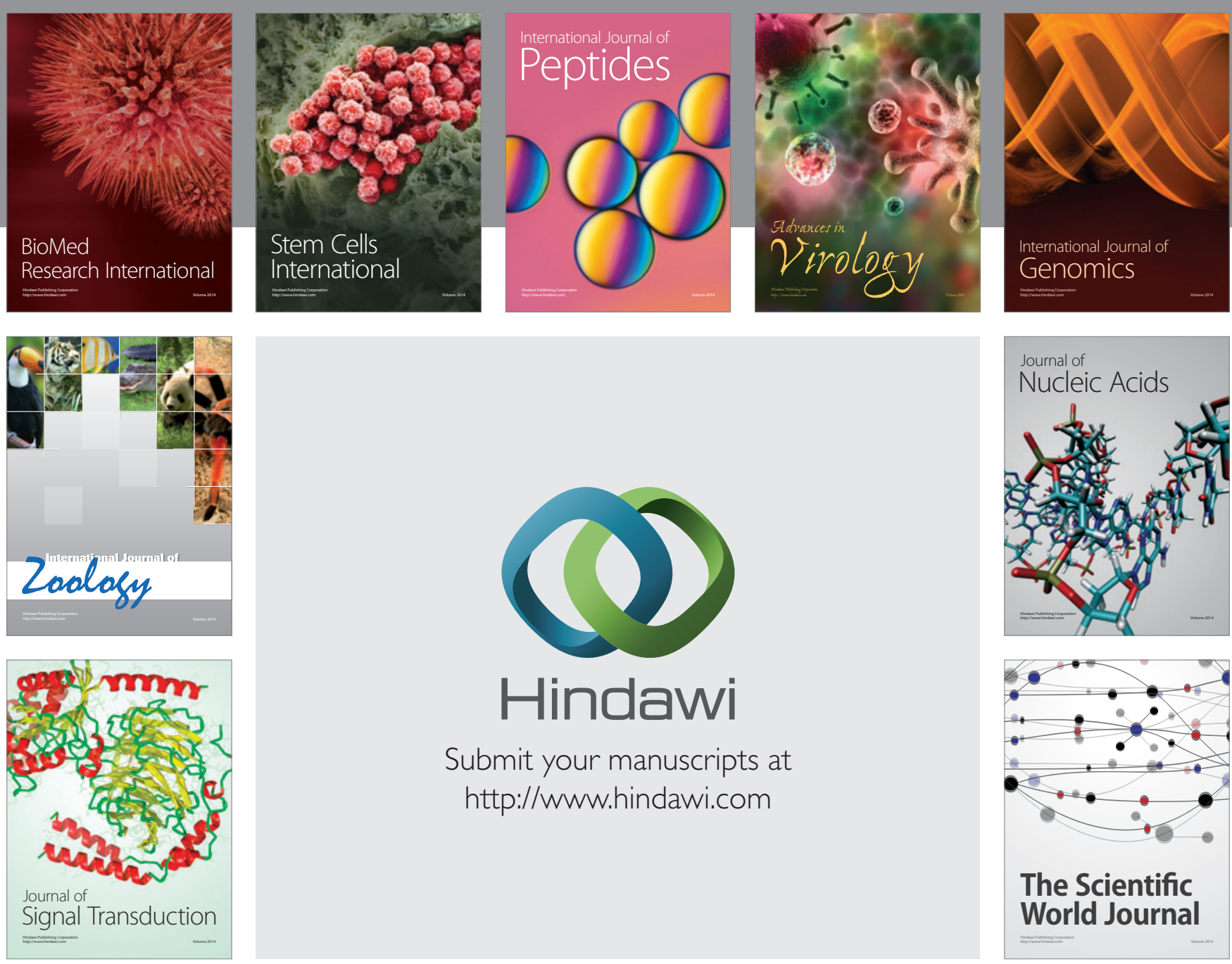

Submit your manuscripts at

http://www.hindawi.com
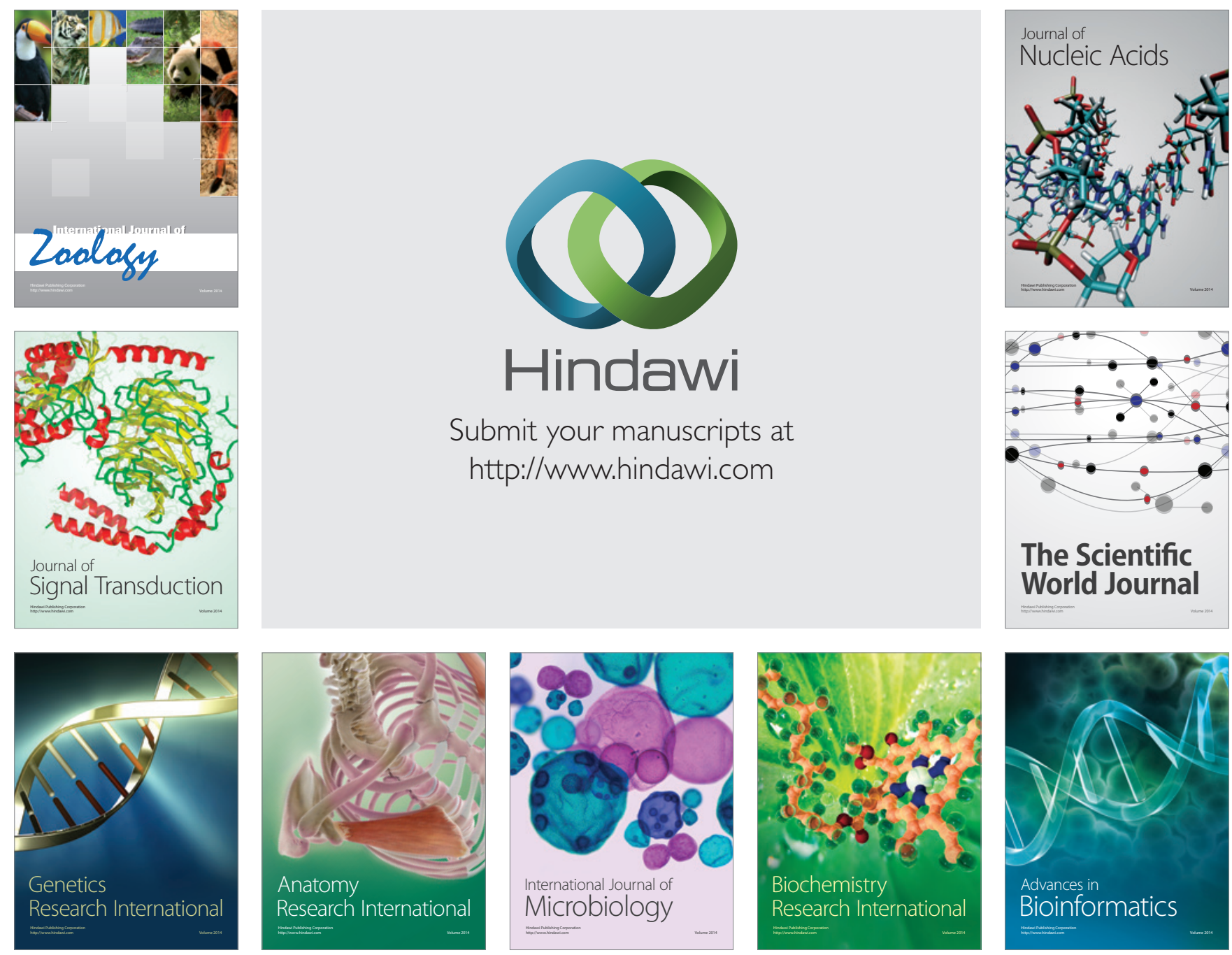

The Scientific World Journal
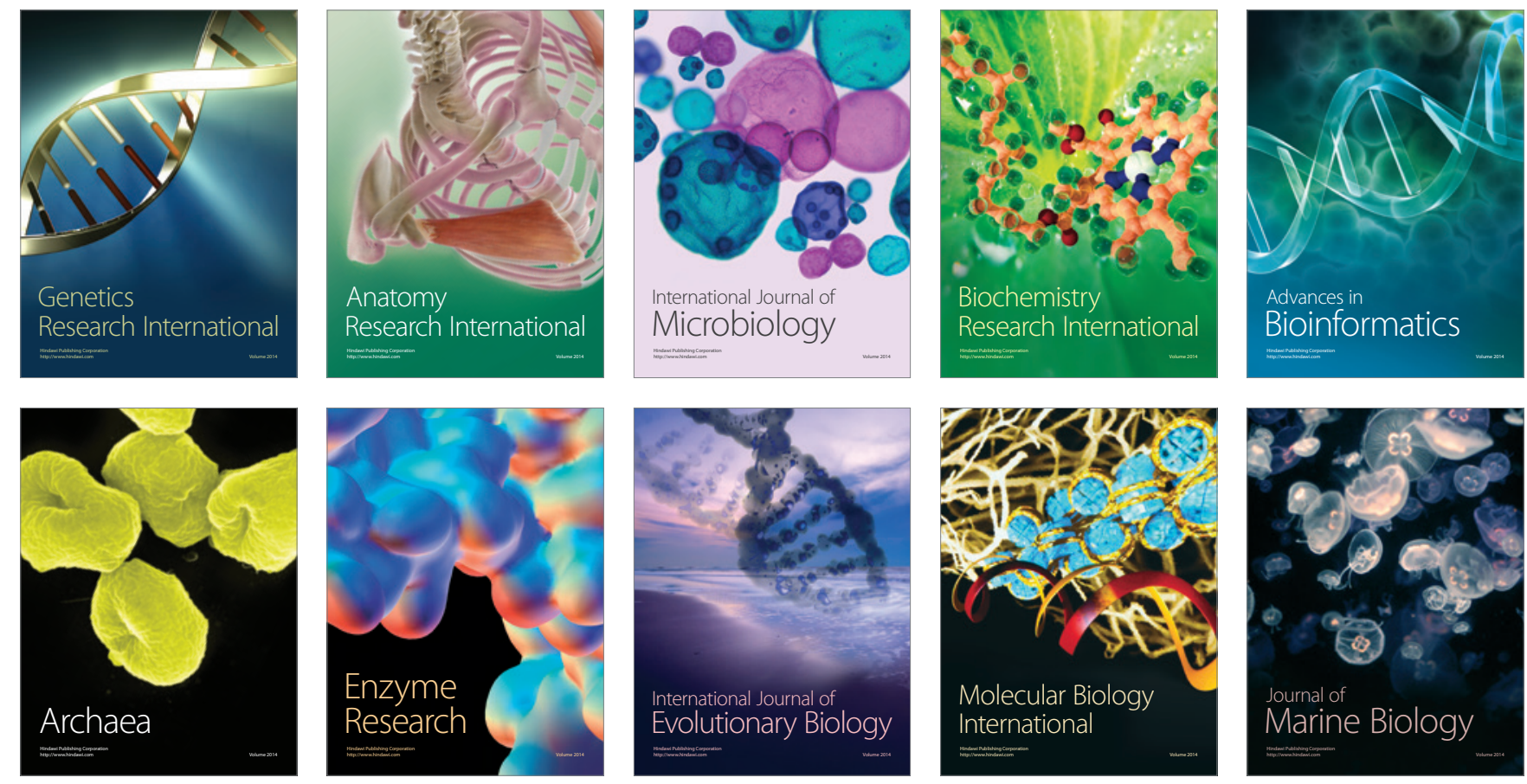